\title{
Cardioverter Defibrillator Shock Therapy
}

National Cancer Institute

\section{Source}

National Cancer Institute. Cardioverter Defibrillator Shock Therapy. NCI Thesaurus. Code C101251.

Delivery of strong electrical impulses by a cardioverter defibrillator to return the electrical activity of the heart to normal. (ACC) 